\title{
Dr. Richard C. Nelson-Mentor and Visionary: Lessons Learned, Memories Forever
}

\author{
Robert J. Gregor \\ ${ }^{1}$ The University of Nevada, Las Vegas
}

\begin{abstract}
Richard C. Nelson started the Biomechanics Laboratory, one of the first of its kind in the world, on the campus of the Pennsylvania State University in 1967. His vision focused on connecting the physiological and mechanical elements of human performance analysis, specifically sport performance. The lab's engaging, interdisciplinary environment supported self-designed programs of study, benefiting each individual student. Furthermore, the Biomechanics Lab became the nexus for the development of biomechanics as a field of study internationally. Richard Nelson's diplomatic skills spread the word initially through the formation of the International Society of Biomechanics. This international effort resulted in the development of national societies of biomechanics around the world, for example, the American Society of Biomechanics. Second, these efforts stimulated the concept of sport performance analysis on the international stage. Richard Nelson's passion was to analyze individual performances at the Olympic Games. This goal was finally realized, with the development of the Subcommission within the International Olympic Committee Medical Commission and biomechanical analysis projects completed at the 1984 Olympic Games in Los Angeles. Richard Nelson's vision, mentoring style, and dedication planted and nurtured the seed of biomechanics as a discipline of study around the world.
\end{abstract}

Keywords: sport, Olympics, mentoring

\section{The Water Tower: Where It All Started}

As a graduate student in exercise physiology in David Costill's Human Performance Laboratory at Ball State University (19691971), influenced by Astrand's and Rodahl's Textbook of Work Physiology, I became interested in movement mechanics. I actually borrowed a 16-mm spring-driven camera from John Cooper at Indiana University and did some "crude" data collection in a "calibrated space" filming runners on a treadmill. We were already doing a great deal of physiological testing (maximal $\mathrm{VO}_{2}$ uptake) on world record-holding marathon runners, and this filming project was my "self-introduction" to what became known to me as the discipline of biomechanics, a discipline I knew nothing about at the time. David Costill recognized my interests in integrating mechanics and physiology and advised me to apply to this new program in biomechanics at the Pennsylvania State University (PSU). He suggested I contact Richard Nelson, Director of the Biomechanics Lab; I visited PSU in the spring of 1971 and was accepted as a student, starting the program the following fall semester. I still remember sitting on the deck at Richard Nelson's house on Park Lane with my wife, our first son, and Richard Nelson and his wife Inez. It was then that I was welcomed into the PSU "biomechanics family" ...4 years of personal and professional growth and great times (lab soccer team, softball team, volleyball team, and the Christmas party). And, interestingly, similar to my running mechanics project at Ball State, the first project I worked on at PSU was a longitudinal study on running mechanics. ${ }^{1}$

Given my interests in integrating physiology and biomechanics, my first impressions of "the lab" on the third floor of the Water

Gregor (robert.gregor@ap.gatech.edu) is with the School of Integrated Health Sciences, University of Nevada, Las Vegas, Las Vegas, NV, USA.
Tower came from the broad range of students I met who were in the program at the time; they had very different backgrounds and interests, and all worked in the same room in the Water Tower. The environment supported exploration, integration, collegiality, and interdisciplinary research. This is exactly where I wanted to be. Richard Nelson, together with Dewey Morehouse, Director of the Sports Research Institute, accepted students interested in human performance, for example, sports biomechanics, sports injury, and exercise physiology. They enriched the faculty in the lab hiring Peter Cavanagh (1972) during my second year in the program. Peter Cavanagh later became my dissertation advisor, teaching me a great deal about skeletal muscle mechanics and experimental design. Ken Petak and the lab's incredible staff very patiently supported all of our experiments. Having centralized technical support is critical to success. I carried that idea throughout my career.

The environment created at PSU embodied the vision of Richard Nelson, an exceptional vision he pursued throughout his career. His approach to mentoring enabled students to focus their energy on individual goals and allowed them to pursue their interests and explore what this new integrated field of biomechanics had to offer. Students developed their individualized coursework (which also included courses required to prepare for the candidacy exam in our program), focused on the development of a good scientific question/hypothesis as well as the methodology (tools) required to address the hypothesis. As each student progressed, each became an emissary of the discipline to the PSU community and the developing field of biomechanics around the world. A good mentor is someone who has a vision for the future, encompassing the areas of teaching, service, and research. A good mentor is someone who listens and guides individuals to reach the goals they have defined for themselves, establishing guardrails as they progress in their career and staying with them as a colleague throughout their career. I learned that from Richard Nelson, an 
excellent mentor. Students are our collective legacy, and Richard Nelson influenced an incredible number of students.

\section{An International Vision: ISB}

Richard Nelson's bold vision for the field of biomechanics manifested itself in many ways. The plaque outside the Water Tower on the PSU campus states, at the start, "Among the first of its kind in the world, Penn State's Biomechanics Lab was established in 1967." The last statement on this same plaque is "The International Society of Biomechanics was founded here in 1973" (Figure 1). These were two major events that occurred early in the history of the development of biomechanics in the United States and internationally, and Richard Nelson was directly responsible for the first and had a marked impact on the second. Details of his involvement in the founding of the International Society of Biomechanics (ISB) are well stated by Benno Nigg and Vladimir Zatsiorsky, in this issue of the Journal of Applied Biomechanics (JAB), in which they discuss the ability of Richard Nelson to collaborate with international colleagues and engage in delicate conversations that required the "diplomatic skills" necessary to attain a collective compromise on several major issues regarding the development of biomechanics as an international discipline. Richard Nelson knew how to talk with people and bring them together. Specific to the ISB, he became the first Vice President and, subsequently, the second President of the ISB. I attended the meeting held at PSU in 1973, where the ISB was more formally established, as a student in the Biomechanics Lab, and will always remember meeting many international visitors who became friends and colleagues as my career progressed. This is the same story many PSU biomechanics students will tell you about their years "in the lab" at that time. Richard Nelson, in his mentoring role, expanded the interdisciplinary environment at PSU, allowing his students to learn the skills involved in international collaboration in academic research - skills I learned and shared with my students and faculty at the University of California, Los Angeles; the Georgia Institute of

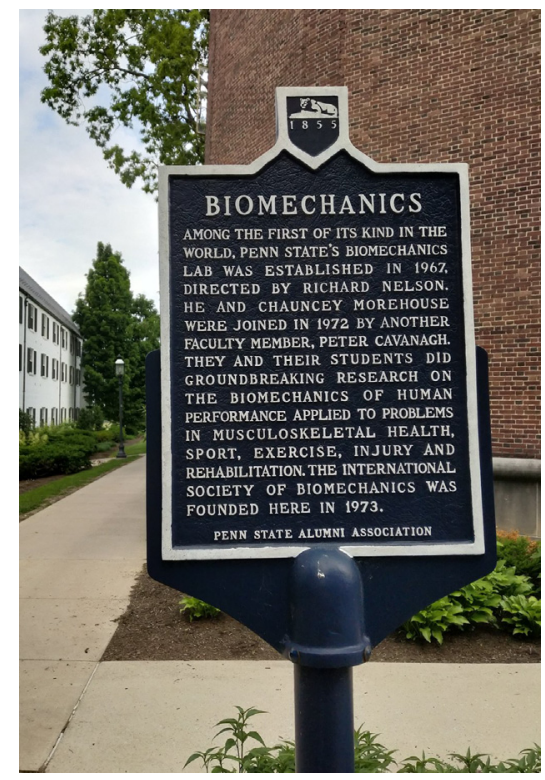

Figure 1 - A plaque adjacent to the entrance to the "Water Tower" at a dedication ceremony on the campus of the Pennsylvania State University in 2009.
Technology; the University of Southern California; and the University of Nevada, Las Vegas.

\section{An International Vision: OFAP}

Along with his extensive involvement in the development of the ISB throughout the 1970s, Richard Nelson's major passion was the development of an Olympic Film Archives Project (OFAP), that is, filming selected competitions at both the Summer and Winter Olympic Games and storing permanent scientific film records of these selected competitions in Lausanne, home of the International Olympic Committee (IOC). Results derived from the quantitative analysis of these films would subsequently be made available to all interested coaches, athletes, International Sport Federations, and so on, as well as to the greater scientific community, to promote the continued development of these sports.

Leading the effort, Richard Nelson began informal discussions regarding an OFAP as early as $1970,{ }^{2}$ with discussions first at a committee meeting of the American Association of Health, Physical Education and Recreation in 1970 and subsequently at the Fourth International Seminar of Biomechanics held at PSU in 1973. While filming at national and international competitions had been conducted informally in the past, an international "filming group," including Jim Hay, Doris Miller (a contributor to this issue of the JAB), and Chuck Dillman, was formed in 1973, at PSU, to better organize and promote the idea of an OFAP. Discussions between Richard Nelson (PSU); Benoit Roy (University of Laval, Quebec City, Canada); Antonio Dal Monte (Istituto Di Medicina Dello Sport, Rome, Italy); Marcel Hebbelinck (Vrije Universiteit, Brussels, Belgium); and Prince Alexandre de Merode of Belgium, Chair, IOC Medical Commission (IOCMC) focused, initially, on possible filming projects at the Montreal Olympic Games. They unanimously supported filming projects to be conducted at the Olympic Games. Major unanswered questions, at that time, were who would appoint the research teams, and who would submit a proposal to the IOC Medical Commission? Inclusion of the IOCMC was critical to obtaining permission from the individual International Sport Federations to film separate events at the Olympic Games, as well as the local organizing committee. While official IOC filming projects were not realized at Montreal, discussions continued, focusing next on the Olympic Games in Moscow in 1980 .

In 1977, Dr. Richard Nelson was invited to present his ideas at the First All-Union Conference on Sports Biomechanics in Tbilisi, Georgia, in the Union of Soviet Socialist Republics (USSR), to make his case for a US-USSR collaboration in sports biomechanics. ${ }^{2}$ Subsequently, a proposal was submitted to the President of the Sports Committee of the USSR, detailing a plan for collaborative filming efforts in Moscow, an exchange of scientists in collaboration with the American College of Sports Medicine and the Scientific Department of the USSR Sports Committee, as well as related financial responsibilities of each party involved. Vladimir Zatsiorsky attended some of those meetings as Director of the Biomechanics Lab at the Central Institute of Physical Culture, located in Moscow, USSR. A historic agreement was finally reached to officially conduct biomechanics film projects at the 1980 Moscow Olympic Games, and, again, Richard Nelson was the driving diplomatic visionary investigator behind this successful effort. In short, Richard Nelson designed a collaborative plan to join together sports biomechanists from the United States and USSR to conduct scientific projects at the Summer Olympic Games in Moscow. These plans were supported by many international organizations and governing bodies, including the United States 


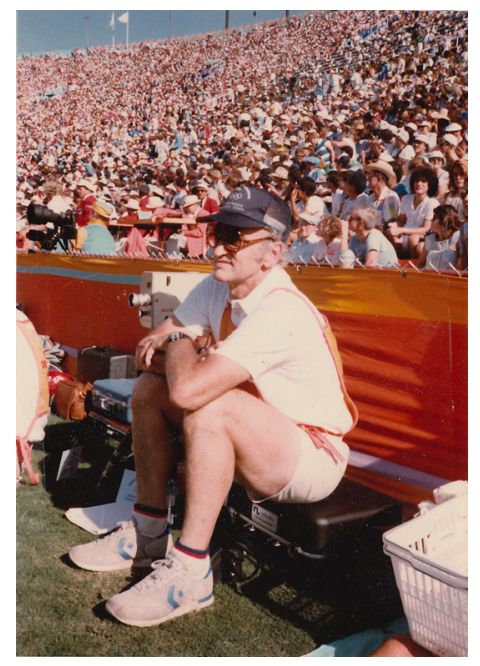

Figure 2 - Richard Nelson sitting by a camera in the Los Angeles Coliseum during the 1984 Olympic games. He is filming the men's $400 \mathrm{~m}$ hurdles.

Olympic Committee, American College of Sports Medicine, ISB, IOCMC, and the sport governing bodies in the USSR.

While events out of Richard Nelson's control aborted these filming projects in Moscow, the stimulus and energy to continue remained, ${ }^{2}$ resulting in the establishment of a Subcommission in Biomechanics and Physiology, IOC Medical Commission, by Prince Alexandre de Merode, Chair of the IOCMC, in 1981. The immediate goal was to conduct filming projects at the Olympic Games in Los Angeles in 1984. Filming projects were organized in track and field, weight lifting, and gymnastics-the same sport disciplines that were actually proposed by Richard Nelson in the original plans for Montreal and Moscow (Figure 2). Results from Los Angeles, and many future Olympic Games, for example Calgary, Seoul, Lillehammer, and so on, were published in the International Journal of Sports Biomechanics, now known as JAB, a journal started by Richard Nelson. The Subcommission increased its membership after the 1984 Los Angeles Olympic Games to support the expanding mission of the IOCMC and biomechanical analyses at the Olympic Games (Figure 3). The Subcommission officially ended its mission in 2002.

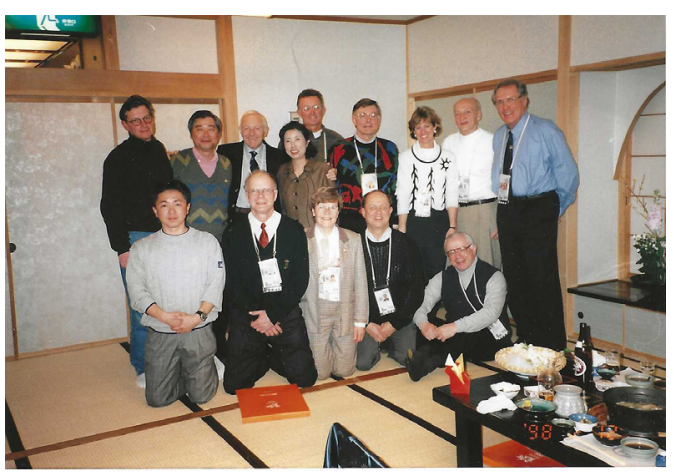

Figure 3 - Members of the expanded Subcommission on Biomechanics and Physiology, International Olympic Committee Medical Commission, at a meeting in 1998. Dick Nelson is standing and second from the right; the author is kneeling second from the right.

Richard C. Nelson's legacy lies in the success of his students (several who have contributed to this special section of $J A B$ ) who passed through the "Water Tower" at the PSU, located in University Park, PA. He exposed his students to a rich, collaborative "new environment," embracing a field in the infancy of its development and taking his vision to reality. The field has certainly progressed from a very exciting "venture" into what has become a very popular integrated discipline. I am very grateful to Richard Nelson for accepting me into the "biomechanics family" in 1972 and instilling the excitement in us all to continue what he started. The experience at PSU was where it all began, and that has certainly changed our collective lives; the stimulus continues.

\section{References}

1. Nelson RC, Gregor RJ. The biomechanics of distance running: a longitudinal study. Res Q. 1976;47:417-428.

2. Nelson RC. Joint US-USSR Olympic biomechanical filming project. In: Scott MG, ed. Citius, Altius, Fortius: Faster, Higher, Stronger. Vol. 14, The Academy Papers. Reston, Virginia: American Alliance for Health, Physical Education, Recreation and Dance; 1980: 20-23. 